\title{
Female genital tract tuberculosis in Tribhuvan University Teaching Hospital: A retrospective one year histopathological study
}

\author{
Abhimanyu Jha, Gita Sayami, Ram Adhikari, Roona Jha. Rashmi Chaudhari'
}

Department of Pathology and 'Dept of Ob/Gyn TU Teaching Hospital.

\begin{abstract}
Aim: To determine frequency of female genital tract (FGT) tuberculosis (TB) in the gynecological biopsies received in the Department of Histopathology of Tribhuvan University Teaching Hospital.

Methods: This is a retrospective study conducted in the Department of Pathology of Tribhuvan University Teaching Hospital. Histopathology records of one year (1 $4^{\text {th }}$ April 2006 to $13^{\text {th }}$ April 2007) were retrieved and searched for the cases of female genital tract TB. Relevant histopathological findings and clinical data were recorded and analyzed.

Results: We analyzed 5696 histopathological cases during one year period for FGT tuberculosis. There were 1565 cases of gynecological biopsy and 9 cases were diagnosed as FGT tuberculosis based on histopathological and clinical findings. Ovarian tuberculosis was seen in three cases, bilateral fallopian tubes were involved in 2 cases and endometrial tuberculosis was diagnosed in 2 cases. 3 cases of omental biopsy and 1 case of peritoneal biopsy showed tubercular granulomas.

Conclusion: FGT tuberculosis was usually seen in age $16-28$ years and constituted $0.57 \%$ of total gynecological cases and $0.15 \%$ of total biopsies. Fallopian tubes, ovaries and endometrium were affected with the involvement of peritoneum or omentum, common event being tubercular endosalpingitis. Histopathology in association with clinical findings still remains gold standard for the diagnosis of FGT tuberculosis in our country despite advancement in diagnostic modalities; however, incidental histological detection in clinically unanticipated cases is not an uncommon event.
\end{abstract}

Key Words: Female genital tract TB, histopathology, clinical findings.

\section{Introduction}

Despite the effective diagnostic and therapeutic measures available, tuberculosis (TB) continues to prevail in developing countries. A report of the World Health Organization shows that there are at present, 20 million tuberculosis patients in the world, of whom approximately three-quarters, that is 15 million, live in developing countries. The number of deaths resulting from this disease is about 3 million per year. At the same time the annual incidence rate of new tuberculosis cases is 2 million. Despite the fact that the methods of treatment are very well known, only one million patients are successfully treated each year. ${ }^{1}$

Tuberculosis remains a major health problem in many developing countries including India and in these countries genital tuberculosis is responsible for a significant proportion of women presenting with infertility. ${ }^{2}$ The actual incidence of genital tuberculosis cannot be assessed accurately in any population, since the disease is discovered incidentally in many patients, and in a large number of asymptomatic patients, this disease remains undiscovered. ${ }^{3}$ It is estimated that world over $5-10 \%$ of infertile women have genital tuberculosis, although this varies from less than $1 \%$ in the United States to nearly $18 \%$ in India. ${ }^{3}$ Genital TB is almost always secondary to a focus elsewhere in the body. In descending order of frequency primary focus is often situated in lungs, lymph nodes, urinary tract, and bone $\&$ joints. The primary focus is most often healed or quiescent by the time the genital TB becomes active. ${ }^{4}$ In descending order of frequency common sites involved by TB are fallopian tubes, ovaries, uterus,

Correspondence

Dr. Abhimanyu Jha, MD,

Lecturer, Dept. of Pathology, Tribhuvan University Teaching Hospital. Kathmandu, Nepal,

Email: jhaabhimanyu@yahoo.com 
cervix and rarely vagina and vulva. ${ }^{4}$ Although tuberculosis is one of the most common chronic infectious diseases in Nepal, and genital tract tuberculosis has been known and treated for many years, the real incidence of pelvic tuberculosis in Nepal is still unknown. Various diagnostic modalities have been used in diagnosis of genital tract TB, but, most often clinical and histopathological correlation is used to diagnose clinically anticipated cases of genital tuberculosis. In present study we have correlated clinical and histological findings in diagnosis of genital tract TB.

\section{Methods}

This is a retrospective study conducted in the Department of Pathology of Tribhuvan University Teaching Hospital, Kathmandu, Nepal. Histopathology records of one year (14 $4^{\text {th }}$ April 2006 to $13^{\text {th }}$ April 2007) were retrieved and searched for the cases of genital tract TB. Relevant histopathological findings and clinical data were recorded and analyzed. Criteria of the diagnosis were histological presence of epithelioid granulomas with or without caseous necrosis and clinical findings.

\section{Results}

Total number of histopathological cases received in one year period was 5696 and out of that 1565 cases $(27.47 \%)$ represented gynecological cases sent from Department of OBG, TUTH. 9 cases of female genital tract tuberculosis were diagnosed histopathologically based on clinical and histological findings (Table 1). Age of the patients ranged from 16 years to 62 years with mean age of 31.66 year. Maximum numbers of the cases were seen in the age group 16-28 years. Female genital TB constituted $0.57 \%$ of total gynecological cases and $0.15 \%$ of total biopsies during one year. Frequency of different sites of female genital tract involved by TB is shown in figure 1 . Ovaries were most common sites to be involved by TB ( 3 out of 9 cases) followed by fallopian tubes ( 2 of 9 cases). In two of the cases both ovaries and fallopian tubes were involved bilaterally, additional omental involvement was seen in of these two cases. In all the cases of fallopian tubes and ovarian tuberculosis typical caseating epithelioid granulomas were seen. Endometrial tuberculosis was seen in 2 of 9 cases. Three cases of omental biopsies (omental biopsy received along with tubal and ovarian specimen is not included here) and one case of peritoneal biopsy revealed typical tubercular granulomas and clinically there were adhesion of uterine adnexae and multiple tubercles in the omentum and peritoneum.

\section{Discussion}

Female genital tuberculosis is not uncommon in countries where pulmonary tuberculosis is widespread. Improved diagnostic techniques (e.g., endometrial curettage and biopsy, histologic examination of curettage, hysterosalpingography, bacteriologic examination of menstrual blood, laparoscopy, and ultrasonography) have resulted in increased awareness of genital tuberculosis. Another trend has been heightened awareness of the potential role of female genital tuberculosis in infertility; this infection has been implicated in $5-10 \%$ of infertility cases. ${ }^{5}$ Tuberculosis should be considered in differential diagnosis of causes of infertility, pelvic mass, and abnormal uterine bleeding, particularly in areas where tuberculosis is common. ${ }^{6}$ Patients with female genital tract tuberculosis are usually young women. ${ }^{7} 80-90 \%$ of patients are diagnosed between 20 and 40 years of age. ${ }^{3}$ In present study age ranged from 16-62 years. $66.66 \%$ of cases were $16-28$ years of age. One case out of nine was postmenopausal. After menopause genital tuberculosis is rare because of decreased vascularity of the tissues. ${ }^{7}$ In the study of Mehrangiz Hatami most patients were in the age groups of 26-30 years. ${ }^{6}$

In this study histopathological tuberculosis were seen in bilateral ovaries and omentum in $33 \%$ and $34 \%$ of cases respectively followed by bilateral fallopian tubes and endometrium in $22 \%$ cases each (Figure 1). Chaudhary $\mathrm{NN}^{5}$ has described fallopian tubes as most commonly affected sites (95-100\%) followed by endometrium (50-60\%) and ovaries (20-30\%). In a study of Bapna ${ }^{8}$ et al fallopian tubes were involved in $72.4 \%$ of cases, but this study included only the cases of infertility. Both tubes are likely to be affected by tuberculosis but endometrial disease may not be always present. ${ }^{9}$ In those cases of omental and peritoneal (one case) involvement by tuberculous granulomas in present study, there were multiple tubercles over uterine and adnexal surfaces at laprotomy. In these cases histopathological examination of fallopian tubes and ovaries would reveal tubercular granulomas if tissue biopsy had been taken. Tubercular peritonitis is seen in combination with female genital tract tuberculosis in approximately $45 \%$ of patients and is responsible for extensive adhesions. ${ }^{10}$

In 5 cases $(55.55 \%)$ in present study, patient had features of tubo-ovarian mass, in 2 cases $(22.22 \%)$ patient had features of ovarian cysts (one unilateral and other bilateral). There were two cases $(22.22 \%)$ with complain of infertility. In one case of tuboovarian mass patient also had complain of infertility and hysterosalpingogram revealed bilateral tubal block. 
Table I. Female genital tract tuberculosis: clinical and histopathological findings.

\begin{tabular}{|c|c|c|c|c|c|}
\hline $\begin{array}{l}\text { S. } \\
\text { N. }\end{array}$ & $\begin{array}{c}\text { Age } \\
\text { (Years) }\end{array}$ & Clinical findings & $\begin{array}{c}\text { Nature of operative } \\
\text { procedure }\end{array}$ & $\begin{array}{l}\text { Sites involved by } \\
\text { TB on histology }\end{array}$ & $\begin{array}{c}\text { Histopathological } \\
\text { findings }\end{array}$ \\
\hline 1 & 42 & $\begin{array}{l}\text { TB abdomen with } \\
\text { tuboovarian mass }\end{array}$ & $\begin{array}{l}\text { TAHBSO with } \\
\text { omental biopsy }\end{array}$ & $\begin{array}{l}\text { Bilateral fallopian } \\
\text { tubes and ovaries } \\
\text { and omentum }\end{array}$ & $\begin{array}{l}\text { Necrotizing granulomatous } \\
\text { inflammation of bilateral } \\
\text { fallopian tubes and ovaries } \\
\text { and granulomatous } \\
\text { inflammation of omentum } \\
\text { C/W TB. }\end{array}$ \\
\hline 2 & 18 & $\begin{array}{l}\text { Left ovarian cyst and } \\
\text { pleural effusion, Adhesion } \\
\text { of omentum and } \\
\text { peritoneum with tubercles } \\
\text { over omentum, } \\
\text { peritoneum, uterine and } \\
\text { adnexal surface. }\end{array}$ & Omental biopsy & Omentum & $\begin{array}{l}\text { Granulomatous } \\
\text { inflammation of omentum } \\
\text { consistent with TB }\end{array}$ \\
\hline 3 & 44 & $\begin{array}{l}\text { Second degree uterovaginal } \\
\text { prolapse }\end{array}$ & Vaginal hysterectomy & Endometrium & $\begin{array}{l}\text { Granulomatous } \\
\text { endometritis consistent } \\
\text { with TB }\end{array}$ \\
\hline 4 & 62 & $\begin{array}{l}\text { Tuboovarian mass } \\
\text { Adhesion of omentum and } \\
\text { peritoneum with tubercles } \\
\text { over omentum, } \\
\text { peritoneum, uterine and } \\
\text { adnexal surface. }\end{array}$ & Omental biopsy & Omentum & $\begin{array}{l}\text { Granulomatous } \\
\text { inflammation of omentum } \\
\text { consistent with TB }\end{array}$ \\
\hline 5 & 28 & $\begin{array}{l}\text { Tuboovarian mass with } \\
\text { adhesion of omentum and } \\
\text { peritoneum with tubercles } \\
\text { over omentum, } \\
\text { peritoneum, uterine and } \\
\text { adnexal surface }\end{array}$ & Omental biopsy & Omentum & $\begin{array}{l}\text { Granulomatous } \\
\text { inflammation of omentum } \\
\text { consistent with TB }\end{array}$ \\
\hline 6 & 22 & $\begin{array}{l}\text { Tuboovarian mass } \\
\text { Tubercles over omentum, } \\
\text { peritoneum, uterine and } \\
\text { adnexal surface }\end{array}$ & Peritoneal biopsy & Peritoneum & $\begin{array}{l}\text { Granulomatous } \\
\text { inflammation of peritoneum } \\
\text { consistent with TB }\end{array}$ \\
\hline 7 & 27 & $\begin{array}{l}\text { Tuboovarian mass, HSG, } \\
\text { bilateral tubal block }\end{array}$ & $\begin{array}{l}\text { Bilateral salpingo- } \\
\text { oophorectomy }\end{array}$ & $\begin{array}{l}\text { Bilateral fallopian } \\
\text { tubes and ovaries }\end{array}$ & $\begin{array}{l}\text { Necrotizing granulomatous } \\
\text { inflammation of bilateral } \\
\text { fallopian tubes and ovaries. } \\
\text { Ovaries destroyed by } \\
\text { inflammatory reaction and } \\
\text { adherent to tube. }\end{array}$ \\
\hline 8 & 16 & $\begin{array}{l}\text { Vaginal discharge with } \\
\text { bilateral ovarian cysts. }\end{array}$ & Bilateral ovarian cyst & Bilateral ovaries & $\begin{array}{l}\text { Necrotizing granulomatous } \\
\text { inflammation of ovaries } \\
\text { consistent with TB. }\end{array}$ \\
\hline 9 & 26 & Infertility & $\mathrm{D} \& \mathrm{C}$ & Endometrium & $\begin{array}{l}\text { Granulomatous } \\
\text { endometritis consistent } \\
\text { with TB }\end{array}$ \\
\hline
\end{tabular}

Abbreviations: TAHBSO, total abdominal hysterectomy with salpingo-oophorectomy; D\&C, dilatation and curettage. $H S G$, hysterosalpingography; $C / W$, consistent with. 


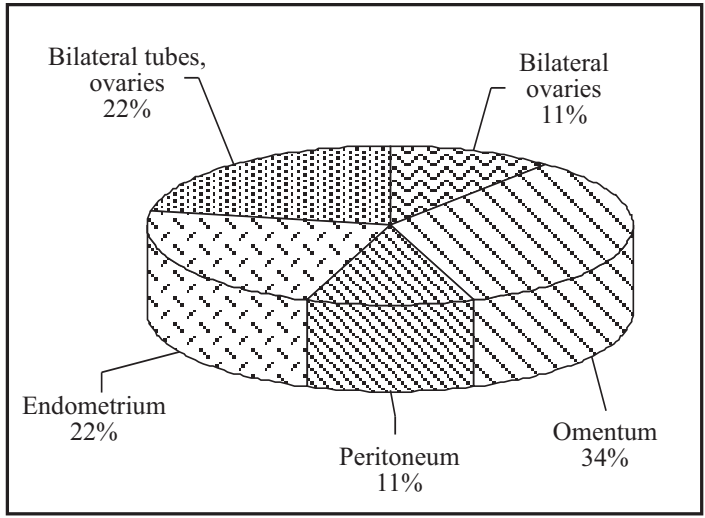

Figure I. Different sites of female genital tract involved by tuberculosis

Diagnostic endometrial curettage in this case showed tubercular endometrial granulomas (Figure 2). Tubercular endometritis in endometrial biopsies of infertile women was seen in $4.97 \%$ of cases in a study by Sharma and Mittal. ${ }^{11}$ Second case of tuberculous endometritis was diagnosed incidentally in a vaginal hysterectomy specimen for uterovaginal prolapse. Fallopian tube constitutes the initial focus of genital tuberculosis in a majority of the cases and tuberculosis has accounted for approximately $5 \%$ of all cases of salphingitis in many parts of the world. ${ }^{10,12}$ The tubes are involved in at least $90 \%$ cases and the disease probably starts there. ${ }^{10}$ The finding of endometrial tuberculosis almost always means that the tubes are infected, although not necessarily closed. But tubercular salphingitis is sometimes found without associated endometritis. The gross appearance varies and is often consistent with chronic salphingitis. Rarely the peritoneal surface of the tubes is studded with tubercles and filled with caseous material. ${ }^{10}$ Dense adhesions are also seen in some cases and frozen pelvis is seen in $17.2 \%{ }^{8}$ Tuberculous involvement of fallopian tubes and ovaries giving rise to tuboovarian mass can mimic tubo-ovarian malignancy. Pelvic tuberculosis can also simulate ovarian carcinoma. ${ }^{9}$ Gupta et al studied 233 cases of ovarian tumor and tumor like lesions and tuberculosis constituted $2.9 \%$ of cases and was the major cause of clinical diagnostic pitfalls for the cases in which clinical diagnosis of ovarian neoplasm was made. ${ }^{13}$

Less common manifestations of genital tuberculosis in women are tuberculosis of the cervix which can mimic carcinoma and donovanosis. Tuberculous ulceration of the vulva is rare. It presents as chronic, painful genital ulceration and may be accompanied by scarring and sinuses. ${ }^{9}$ As we took one year data, tuberculosis of cervix is not recorded which has been seen in earlier years and also vagina or vulva which is very rare.

Despite the advancement in the diagnostic modalities histopathological diagnosis of female genital tract tuberculosis remains gold standard in both clinically anticipated and unanticipated cases Histopathologically tubercular lesions show typical epithelioid granulomas with or without giant cells. Caseous necrosis as well may or may not be seen in the sections. In addition to typical granulomas there may be secondary changes in the tissue such as fibrosis, suppuration and destruction of the normal architecture of the tissue. In present study in all the cases typical epithelioid granulomas were seen. Caseous necrosis was seen in the cases of ovarian (Figure 3) and fallopian tube involvement, while it was not seen in the omental, peritoneal and endometrial lesions. Fallopian tube tuberculosis may show features of either tubercular endosalpingitis (Figure 4), tubercular exosalpingitis or interstitial tubercular salphingitis, as it was seen in present study. ${ }^{4}$ In the former tube is thickened, enlarged and tortuous. When fimbrial end remains open although rare, can lead to involvement of peritoneum due to periodic spill of the tubal exudates into the peritoneal cavity. If both the ends of the fallopian tube can sealed off as a result of fibrosis, caseation in the wall and collection of caseous material in the lumen leads to formation of pyosalpinx. Dense adhesions often develop around such a pyosalpinx, involving bowel, omentum, ovary, and uterus. In absence of adhesions such pyosalpinx may remain mobile giving rise to an abdominal lump simulating ovarian cyst. ${ }^{4}$ Tubercular exosalpingitis is characterized by tubercles on the peritoneal surface (Figure 5) and interstitial tubercular salphingitis shows granulomas within the wall of the tubes. ${ }^{4}$ In present study as well similar features are seen in two cases involving bilateral fallopian tubes and ovaries. Classic tubercular pyosalpinx was seen in both the cases with adhesion and destruction of the normal architecture of the ovaries. In one of these two cases omentum was

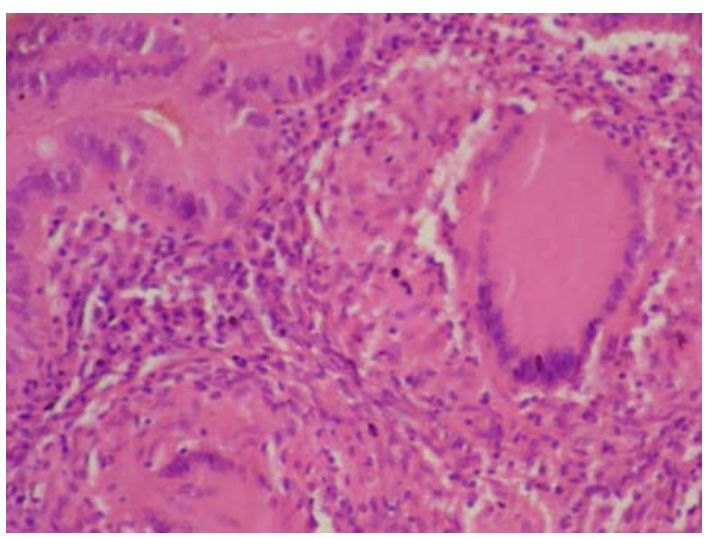

Figure 2. Endometrial tuberculosis:

Well formed typical epithelioid granulomas with typical Langhans giant cells within the endometrial stroma. Chronic inflammatory cells are seen surrounding the granulomas. Altered endometrial glands are seen at left upper corner of the field. (Hematoxylin \& Eosin, 400X) 


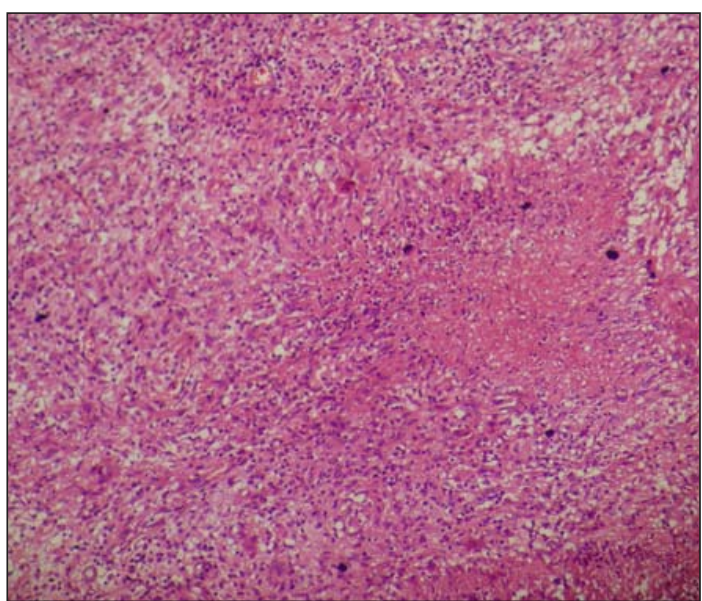

Figure 3. Ovarian tuberculosis:

Epithelioid granulomas with central caseous necrosis (homogenous pink appearance, slightly right to center of the field). Ovarian stroma shows chronic inflammatory cell infiltrate and fibrosis. (Hematoxylin \& Eosin, 200X)

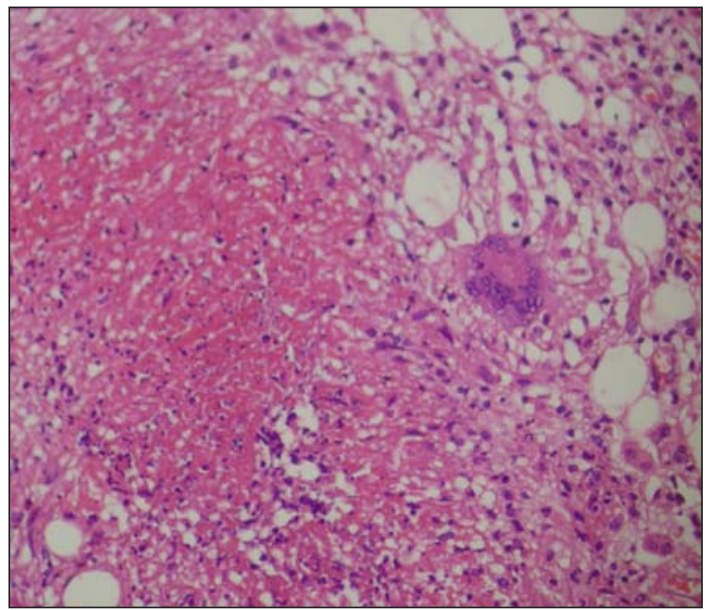

Figure 5. Tubercular exosalpingitis: Peritoneal surface of the fallopian tube shows extensive areas of caseous necrosis, surrounding epithelioid cells and Langhans giant cells. Adjacent adipose tissue shows fibrosis and chronic inflammatory cell infiltrate. (Hematoxylin \& Eosin, 200X)

adherent and showed tubercular lesion. Ovaries were completely replaced by fibrous tissue, caseating granulomas and neutrophilic exudates. In these cases peritoneal surface of the tubes and ovaries also showed typical tubercular lesions, in addition in one of the case wall of the paratubal cyst also showed epithelioid granulomas (Figure 6). Fallopian tube showed epithelioid granulomas within the mucosa (Figure 4),

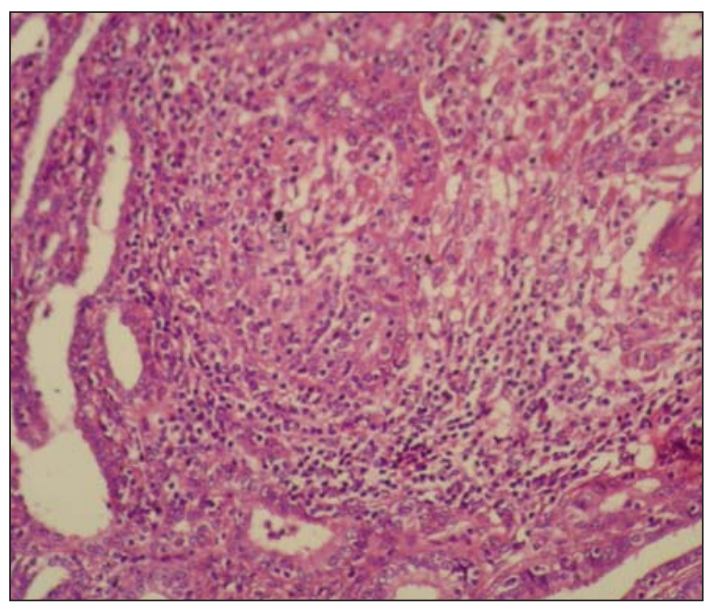

Figure 4. Fallopian tube tuberculosis: Tubercular endosalpingitis showing well formed epithelioid granulomas within the mucosa of the fallopian tube. A few chronic inflammatory cells are seen surrounding the granulomas. Tubal mucosa at the periphery of the field shows deviation from the normal pattern. (Hematoxylin \& Eosin, 400X)

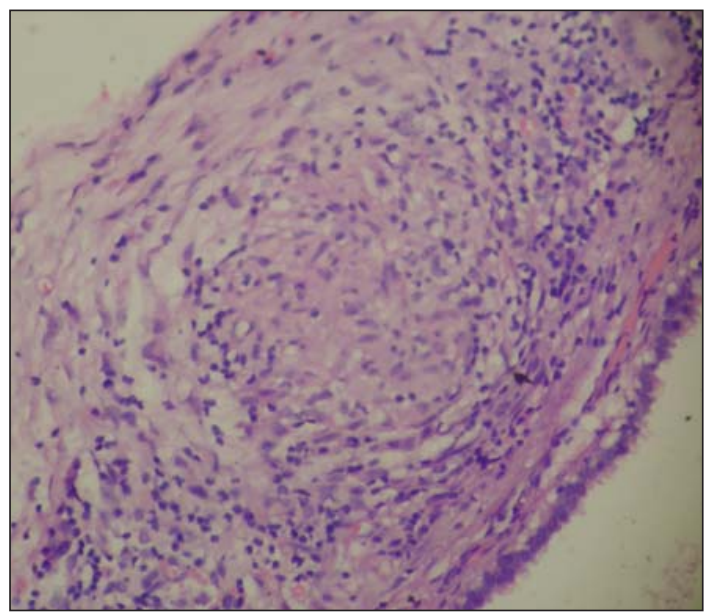

Figure 6. Wall of the paratubal cyst showing epithelioid granulomas. Lining epithelium of the paratubal cyst is seen at the right lower corner of the field. (Hematoxylin \& Eosin, $400 X)$

in the wall and over peritoneal surface (Figure 5). What starts as tubercular endosalpingitis may end up as a tubercular peritonitis as it was seen in present study where all the three forms of tubercular salphingitis were seen. ${ }^{4}$ In this study both the cases of endometrial tuberculosis histologically showed non-caseating granulomas with alteration of glandular architecture. Endometrial glands were crowded and showed slit like 
features. Granulomas were seen in the interstitium and showed numerous typical Langhans type of giant cells surrounded by epithelioid cells and chronic inflammatory cells (Figure 2). Hoff et al reviewed 11 cases of granulomatous endometritis and none of the cases revealed caseation as in the present study. ${ }^{14}$ It has been hypothesized that tuberculous granulomas in the endometrium are sometimes not necrotic because of the turnover rate of these tissues as part of the normal menstrual cycle. In non-endometrial tissue or in postmenopausal women, however, this would not be a factor and some evidence of caseous necrosis might be expected. Absence of Acid fast bacilli as demonstrated by Ziehl-Neelsen stain does not preclude the possibility of tuberculosis. ${ }^{14}$ However, a clinical correlation is required to rule out other lesions producing endometrial granulomas such as fungal, viral and parasitic infections, sarcoidosis, vascultitis, foreign body reactions, radiotherapy, ceroid accumulation, and previous instrumentations. ${ }^{14}$ In a study by Reys and Maheshwari involving 500 endometrial biopsies no characteristic endometrial pattern was found to be specific for a tuberculous lesion. A deviation from normal pattern such as proliferative, mixed and hyperplastic endometrium was noted in number of cases. The tuberculous lesion was found to be diffuse with caseation in amenorrhea cases while a focal noncaseating was a feature with normal cycles. ${ }^{15}$ An appropriate sample is required for accurate diagnosis of endometrial tuberculosis. Curettage should be carried out in the late premenstrual phase from the cornu of the uterus. This because tubercles are present in the superficial layers and are shed during menstruation and cornual end is the first part of uterine cavity to be affected by descending infection from the fallopian tubes. ${ }^{4}$

\section{Conclusion}

Female genital tract tuberculosis is a common cause of morbidity in the developing countries like Nepal. Most of the cases remain silent for many years and detected in course of investigation for infertility or pelvic and abdominal mass. It is often seen in young female in their reproductive age. Maximum numbers of the cases in present study were seen in the age group 16-28 years. In present study female genital TB constituted $0.57 \%$ of total gynecological cases and $0.15 \%$ of total biopsies during one year. Fallopian tube, ovaries and endometrium are the common sites to be involved as it was seen in present study. Secondary involvement of peritoneum and omentum as a result of tubercular endosalpingitis is also a common event and was seen in present study. Histopathology in association with clinical findings still remains gold standard for the diagnosis of female genital tract tuberculosis in our country despite advancement in diagnostic modalities.

\section{References}

1. Repond R. Tracking down tuberculosis. WHO $1974 ; 28-33$.

2. Muir DG, Belsey MA. Pelvic inflammatory disease and its consequences in the developing world. Am J Obstet Gynecol 1980;138: 913-28.

3. Schaefer G. Female genital tuberculosis. Clin Obstet Gynecol 1976; 19: 223-39.

4. Padubidri V, Daftary SN. Tuberculosis of the Genital Tract, in: Howkins \& Bourne, Shaw's Textbook of Gynaecology, edition 11. New Delhi, B.I. Churchill Livingstone. 1994; pp 155-164.

5. Chowdhury N N. Overview of tuberculosis of the female genital tract. J Indian Med Assoc. 1996; 4: 345-6, 361 .

6. Mehrangiz Hatami. Tuberculosis ofthe female genital tract in Iran. Archives of Iranian Medicine $2005 ; 8: 32-35$

7. Gungorduk K, Ulker V, Sahbaz A, Ark C, Tekirdag AI. Postmenopausal tuberculosis endometritis. Infect Dis Obstet Gynecol. 2007; 2007: 27028.

8. Bapna Neelam, Swarankar Mohanlal, Kotia Namita.Genital tuberculosis and its consequences on subsequent fertility.J Obstet Gynecol Ind 2005;55:534-537.

9. Richens J. Genital manifestations of tropical diseases. Sex Transm Infect 2004; 80: 12-17.

10. Varma TR. Genital tuberculosis and subsequent fertility. Int J Gynaecol Obstet 1991; 35:1-11.

11. Sharma SP and Mital VP. Incidence of endometrial tuberculosis in sterlity cases in Eastern U.P. Indian Journal of Tuberculosis 1979; 26: 157-159.

12. Novak ER, Woodruff JD. Novak's Gynecologic and Obstetric Pathology, 8th edn. Philadelphia. WB Saunders. 1979; pp 328.

13. Gupta N, Bisht D, Agarwal AK, Sharma VK. Retrospective and prospective study of ovarian tumors and tumor-like lesions. Indian J Pathol Microbiol. 2007; 50: 525-7.

14. Hoff Elise, Prayson Richard A. Incidental Granulomatous Inflammation of the Uterus. South Med J 2002; 95: 884-888.

15. Reys $\mathrm{H}$ and Maheshwari HB. Tuberculosis of the endometrium: a histopathology of 500 biopsy cases. Indian Journal of Tuberculosis 1971; 18: 27-33. 